\title{
Governing: A Philosophical-historical Account for Some Modern Deficits of Public Administrations (Public Policies)
}

\author{
Dimitris K. Kioukias \\ Department of Administration of Business and Organizations, Faculty of Social Science, Hellenic Open University, Patras, Greece \\ Email address: \\ kioukias.dimitrios@ac.eap.gr \\ To cite this article: \\ Dimitris K. Kioukias. Governing: A Philosophical-historical Account for Some Modern Deficits of Public Administrations (Public Policies). \\ History Research. Vol. 7, No. 2, 2019, pp. 77-84. doi: 10.11648/j.history.20190702.17
}

Received: November 4, 2019; Accepted: December 17, 2019; Published: December 27, 2019

\begin{abstract}
In our view, who the real policy makers are as well as which the particular premises upon which a public policy is based have not been abundantly clarified. The fact that there are often plural possible alternatives available before decision on a critical issue is taken suggests the multidimensional character of public policies. Which choices shall be eventually made is a very interesting issue which merits attention. This calls for an analysis of the concrete principles governing a public issue. Quite often plural principles may be discovered around a public issue. Policy makers have then to choose among them the right one. While achievement in the respective area cannot be denied, some public policy decisions (outputs) may still leave much to be desired. Examples may be taken from numerous policy areas. The aim of this paper is to address such concerns and try to provide explanations of a classical philosophical character. To this end it rests upon such assumptions: a. Decisions are stemming from ideas represented by verbal utterances. Material conditions by themselves cannot produce such ideas, for good knowledge of a language is required. They are not irrelevant, but they are not producers. b. Principles (ideas) often clash with each other. Priorities then must be placed (rule of selecting the right principle for each case).
\end{abstract}

Keywords: Philosophy of Public Policy, Multidimensional Public Policy, Fresh Views, Issues

\section{Introduction}

Testing public administration performance is usually based on accepted criteria originating from definitions discussed and accepted by social science and policy makers. At the end of the day public policies originate from ideas-principles, as we shall try to prove. In addition, public administration is divided into policy areas and checked according to standard criteria. Unemployment policy is judged on low rate achieving; insurance/social security policy is judged on low cost/wide coverage percentages; education policy is judged on high coverage, etc.; and environment policy is thought to be good if pollution is diminished, or rate of substitution of environment unfriendly technologies.

To be sure qualitative criteria have not been totally extinguished. Who and what one gains under what terms is still of concern. If a particular measure is justified in terms of human cost is also a matter of interest, as "good legislation" practices suggest.

Yet, the so called "arithmetic equality", a term first coined by Aristotle [1], has gained considerable ground, as it has been reinstated in policy issue terms. Some of the reasons for this development will be suggested in this paper. However, its main aim is to show how in some cases such approaches can affect the lives of the recipients less than desired. More targeted and more sophisticated approaches seem to be in demand. At the same time, in some policy areas what is required is wider and relatively objective treatment. As a horizontal approach cannot apply everywhere, it seems that certain vertical-hierarchical approaches should also be applied. After all mathematics - a revived tool for objectificationinvolve both dimensions.

As I have pinpointed elsewhere [2], scientists' warnings are quite common, for they enrich the more enforceable-prescriptive-part of a scientific branch. I see we cannot easily escape this path, but I shall try to avoid some exaggerations. I shall try to focus on real inadequacies observed at the level of decision making. From this point of view, "some deficits of public administrations" is in itself some kind of overstatement. After all, major decisions are taken by the cabinets with civil services trying either to implement them, or, in some cases, veto them. On the other 
hand, public service properly understood is a term which includes the higher echelons of power. In addition, in a participatory democracy decision making involve lower rank cadres.

In trying to state our case we shall focus on, first, logical-linguistic factors and, secondly, ideological ones. Moreover, to sustain our argument, we shall select particular issue areas such as foreign policy making and parts of domestic policy making. Nowadays, these two are, of course, interwoven, due to the existence of a multilevel governance. Thus, quite often decisions are made not exactly rationally, but with a strong inference to foreign audiences and expectations. Domestic issues are increasingly shaded by international relations. This is no novelty, of course, but the problem has become far more intense. In any event, within a framework of a kind of "brainstorming", policy outcomes cannot be rational. Similar outcomes are to be expected under pressure by globalized ideologies. More concrete examples will be offered below.

\section{The True Origins of Public Policies}

We normally suppose that public policy decisions originate from specific policy makers and administrations (governments). As policy outcomes, such decisions take the form of legal policy instruments, if sometimes are based on bilateral (collective) agreements. This is not wrong prima facie. On the other hand, as rational options which aim at rationally regulating human relationships, they cannot but stem from reason. Policy decisions after all must be "negotiable", hence communicative, in order to be discussed publicly, defended and justified upon request. They are not just raw demands, as political science suggests [3].

As a product of reason and hence thought, aiming moreover at regulating complex human relationships, they cannot but be a product of intellect. In such terms, ideas guide the making of policy decisions. For an idea is not just a random thought, but an elaborated thoughtful scheme. If we apply ideas at random, we shall have random, i.e. uncontrollable results. Political power, however, has never been known for having a relationship with lack of control; quite the opposite. Control here is not used in the sense of a will to rule, but rather as a synonym to organization. For what must be reproduced and consumed must be somehow organized. Administration is after all a system of subdivisions based on the idea that less is better controlled (usable) than more. Public administrations are for such reason divided into policy areas departments. As the Greek thinker Aesopus had put it, "bad results come from a state in which everybody deals with everything" [4].

Such "small" ideas must be put into an easily communicable language, as parliaments and courts look forward to further controlling them. As we implied earlier, they are in need of some kind of legal language which offers both communication and enforceability. This language based on long practice becomes recognizable by nearly all, while it, at the same time, bestows original ideas with a particular form which contains sanctions, without which they would remain just vague ideas. From this point of view, law as a language suggests an implementation function, for legal investment helps political ideas to become implemented. That is why we normally treat politics as a practical art. They do, however, originate from abstract thinking. Moreover, they must keep some measure of such thinking, as a true law must be general and impersonal (source). A very specific law would jeopardize its objectivity. This idea is again borrowed from philosophy and science which tend to invent scientific laws, i.e. valid generalizations. That is precisely objectivity. Rather than suggesting infallibility, it aims at valid generalizations.

We most often than not tend to talk about administrative principles, rather than ideas. For instance, a charter of rights, is a declaration of (ethical) principles. Even Economics, or private management fields, are based on principles. Economic efficiency and cost avoidance in the management of services are quite common principles. In other words, we avail the right (possibility, permission) to administer in a rational (excessive cost avoiding) way. Put this in negative terms, it means we are not allowed to spend irrationally, or we shall run the risk of doing injustice to some resources (human resources included). A "principle" then is like a right, mostly known as a subjective law, for it refers to the just cause of usually a social group, or an individual. Surely, there are also objective rights-often encapsulated in penal law, despite the existence of some opposite views [5]. I believe such rights are those which protect against insults to body and mind integrity (if we treat such fundamental rights as relational upon historical phase and power relations, we shall risk "losing" all human rights edifice). On the other hand, we admit there are "relational" rights, for right is like "power" which is either objective, or relational [6]. Indeed, quite often some new rights clash with other rights-very much like a new legal statute clashes with an older one. Such a conflict signifies their relativity, for an absolute power does not depend upon some other power.

Such focus on ideas is sometimes opposed as pure idealism. The defendants of materialism accept that ideas are a byproduct of material conditions. The latter quite often do shape our ideas, for otherwise we would not accept the notion of interest, or the idea of the "economy". Nonetheless, material conditions do not speak by themselves, in other words our environment does not dictate options to us. Instead we are in need of a translator, a consultant. We are also in need of a suitable language. Such intermediaries are called ideas, as they make reality intelligible.

\section{Some Critical Factors Affecting Public Policy Decisions}

As public policies originate from ideas and principles which are invented by intellectuals and scientists and translated into policy formulas by legal experts, their validity depends upon good scientific work. For example, the more logical coherence and good language is applied, the better the legal-political outcomes will be. To that end a good knowledge of all the policy areas and their interconnectedness is required. This factor is often 
approached through the creation of interdisciplinary panels, or institutionalized committees. As, however, old studies have shown, the vital role played by sectoral interests, or personal ambition (e.g. Allison [7], Owen [8], Churchill [9]), there is need of a chief arbiter. Therefore, as we know, final decisions-choices are made by the politicians. The latter are not technical experts necessarily, therefore they must return to ideas and principles. They may not understand all technical details of the legal formula, but are in a position to judge a technical decision in principle. After all, the term itself denotes some predominance. A principle is a rather general idea and as such predominates over smaller ideas-details. For, the whole, however vague might appear, is still the whole, while the details are parts which may suit this, or that case invariably. There are, of course, some crucial details which may merit special attention, as in the case of an international treaty. A good politician must then be in a position to capture both the whole and crucial parts. In most of the cases, however, more crucial than the means of a plan is its main purpose. Thus, a chief is one who understands principal purposes. Such are, for example, prosperity and survival of the larger number of a country's inhabitants, as suggested by some classical philosophers, say Rousseau, or Bentham. To the former [10] a government which fails to provide general prosperity, abandoning citizens' fate as a main goal is the worst kind of government. Mutatis mutandis a good supranational government is one which cares most about its citizens' prosperity.

A politician must be in a position to know the factors upon which an individual's well-being is dependent. After all, such principles appear as a first chapter in modern constitutions. Basic protection of life is thus a top principle. On the other hand, some "failures" in this respect are owed to a predominant now frenzy style of policy making, as audiences appear extremely impatient, whilst "e-government" is on the one hand a cost reducing resource, but, on the other hand, an intolerant means, as far as time and space is concerned. As has been put on other occasions, e.g. discussing globalization and risks, time and space are considerably reduced under conditions of extreme speed. Policy makers appear now as if they navigated a space ship, for every mistake is instantly multiplied and magnified, just like small sounds in Space. It was not accidental that film title, "Space Odyssey", for extreme pressure contributes to transforming time and space into an infinite journey. We shall return to this issue later (concluding sector). Finally, political pressure often contributes to the technical perfection of an issue (say survival) at the expense of its, even imperfect, realization. It is no coincidence that, while macroeconomic and fiscal aspects are usually well measured, the potency for survival of a human unit is neglected from this point of view. This is absolutely understandable from a technical point of view-what politicians must foremost be accountable of is balanced budgets-yet it is still a failure.

\section{Some Misconceptions}

The efforts towards making more effecive policies have been intensified over the last decades with a special emphasis placed on economic/cost reducing principles. Still it does not seem that the aim of justly legislating has been abandoned altogether, as social principles and "new politics" have been inserted into the notion of good law/legislation. According to the latter, a law must reflect all prevalent values at the same time, even if its subject is much narrower. Such are across the spectrum equality and "new values" such as environmental ones and protection of minorities. It seems that the key idea that values (principles) often clash with each other [11] is no longer held- though we prefer to abandon traditional values. This may have been adopted as a benign gesture toward contemporary consensus party systems, as especially reflected in modern constitutions (they in fact horizontally prescribe all kinds of rights). Yet, do catch all policies of such kind reflect reality? Have we abandoned the key idea of politics as a zero sum game? Has it ever occurred to us that this submission to value consensus might constitute a kind of populism?

In trying to reply to such allegations we shall choose to discuss the matter in accordance with some key principles mentioned previously. Thus, if we wish to apply equality (arithmetic equality in particular) to every public policy, we shall reach a point of reductio in absurdum. Especially policies which attempt to boost best qualified labor selection are in contradiction with such a principle. Arithmetic equality here, if literally applied, would suggest the purposeless of higher education which to a large degree is based on the principle of merit and is by definition a hierarchical system. Indeed both traditional and new evaluation systems are based on ratings. Marks are also signs of rating. The very term "qualification" which is up to a certain extent an objective value measure in order to place someone to a certain job (e.g. in public administration) would be rendered meaningless under an arithmetic equality regime. Then the role of education as a developmental tool would disappear. Instead, experience would only count.

We might indeed call arithmetic democracy, as applied to various sectors, a populist system. For, populism is a policy, or a strategy, which tries to appeal to all segments of society with promises for welfare, regardless of further qualifications. Thus, a populist democracy is an unqualified democracy, or, to put it in other words, a non- procedural one. Whereas, well institutionalized democracies apply equality to the latter aspect (legal equality), populism is concerned with a results oriented equality. Last, we should mention that a populist spirit may and indeed does spread to all sorts of public policy, e.g. culture, education, family, etc. As has been pointed out [12], the organizational form of populism is a loose institutionalization marked by a lack of intermediary social institutions such as family, or civil society. It is because of such features, we thought it is a statisizing and extremely authoritarian system. This might appear as a major paradox, but let recall ancient Greeks' ideas: "Tyranny comes out of extreme-read arithmetic-democracy" (Plato [13]); "Tyranny is a preventive democracy" [14]). We must add though that this is not about a two way relationship; any kind of authoritarianism is not to be equated to populism.

Indeed similarities do not amount to identities. Systems of 
authority may also be distinguished from each other, due to more or less subtle peculiarities. If these were not, there would not be any need to use different terms. Thus, we normally distinguish between overt authoritarian systems from covert ones, as the former are marked by open authoritarianism, while the latter are a result of extreme liberty. For example, violence and its particular manifestation, i.e. "bullying", may result as much from preaching violence as undermining of deferential values. However, in the first case there is an overt pro violence rhetoric, while in the second case there is a pacifistic rhetoric albeit not matched by similar practices. In such cases, it does not behoove policy makers to cultivate deference values. For, as often has been pointed out, any kind of authority has been undermined [15]. Too much emphasis on "horizontal measures" (usually egalitarian ones) cannot create respectfulness. Take, for example, the emphasis placed by teaching agencies on "generation gap". This has led to rather snobbish stances toward the elder, even when they have been appointed as teachers. Lately this fallacy has led to policies against them, as in the labor market and political careers. Definitely, such policies may rightly be treated as populist ones, as they are non-hierarchical and irrational at the same time. They are also quite "flattering'. A more rational attitude toward the matter would entail accepting the natural course of life which in turn entails not just decay, but also comparative advantages. The Greeks used to say that mental power increases over the years. In addition, if we accept the notion (function) of maturing-and we certainly do, we must accept the age factor too. If we accept the idea of thrill (we do, as cinema star admirers), we will accept the idea of gap too. For a thrill is made, not just out of merit, but distance too. A human being is bound to admire what is at distance, either in time, or space (cf. with Aristotle's suggestion in his "Rhetoric" [1]). Remote objects (or subjects in this case) usually capture human imagination. The latter is also an exercise in capturing remote things and make them intelligible, i.e. our own. (To "own" comes close to mean to annihilate remoteness. Similarly, to govern (in Greek archo-archi) means to be placed in a prior position in relation to others and hence to be able to imagine (in order to capture what is not easily visible-thus the term dioratikos). It is surely no coincidence that a great ancient Greek legislator was called Zaleykos, in other words dialeykos (inter-white light), a word which is a synonym to dioratikos [14].

Therefore, a good grasp of the language and its subtle shades is to us an indispensable faculty in order for one to apply public policies. Consequently, political art, as a legislative stage, is an intellectual art. The policy implementation functions, are, of course, matters of will and communication. Yet, policy implementation, as we saw, starts from the pre-legislative stage.

To be sure, most of the public policies put forward at times must have been good. In the $20^{\text {th }}$ century standards of living have been growth considerably and democracy has been spread widely. On the other hand, questions about good administration are still raised, for, after all, we live in the era of a "regulatory state", or a new "Reformation", so to speak. To criticize public administrations is often a matter of ideology, i.e. a disagreement over ends. What is less discussed though is judging public policies upon logical consistency, save for the relative problems arisen from many contradictory laws. It must be noted on this occasion that "polynomia", according to ancient Greek political thought, used to be met with skepticism, as it was regarded as a fatal blow against political authority itself. If decisions frequently change, the authority which makes them must be a superfluous "mind" and "soul". Indeed, when we are not sure about a thing, we are usually between two minds. To legislate our ambivalence is not very wise. Anticipation of clear ends and clear means is then a political virtue. The latter in turn is akin to knowledge. If we do not know well, we will certainly fall to inconsistencies. It is more common that a politician happens to have a superficial grasp of the subjects than to be a liar. Logical contradictions stem much more from lack of logical coherence than expedience-though the latter is also common among extremely populist leaders.

On the other hand, as the Greeks had pointed out, a successful administration is based on both sides, i.e. leaders and led- the latter include civil servants of various ranks. Some problems may arise from an entrenched belief in results oriented management and sheer regulation. We do not, of course, dispute the value of effectiveness, as, at least in so far as the Greek system is concerned, bureaucratic obstruction was among others associated with petty legalism and abuse of procedural routes. However, effectiveness should not be as much separated from causal-rational explanation as to reach a point that law must be disregarded. In democratic systems we unfortunately have to go legally, not just quickly. Illegal pursuit is, after all, labeled as corruption. Moreover, the problem of legal-bureaucratic barriers to investments is a matter which cannot be remedied just through less legal control and accountability. We may thus risk abandoning the rule of transparency. On the contrary, we believe that in some policy areas more transparency is required, as, for instance, in the case of the true technological capacities of modern states. This is an imperative nowadays, as the penalties enforced upon wrong doers are massive. As some penalties impose considerable economic burdens, would be wrong doers should be in a position to know in advance what is permitted and what is not. What is more, to appear to regulate things through modern custom amounts to an extremely effective tool. Thus, effectiveness without legality (written law included) is, in my view, another misconception. Let me remind here that the reason why in past times legality was developed was exactly the need to bind political decisions with "causes". This, apart from enhancing justice, has the merit of making decisions more rational, i.e. more scientific. In his familiar "fictional empiricist" way [16] Socrates defined science as an inhibition to let "Daedalus statues" escaping at night. Probably based on this allegory, John Locke later on termed his desirable state as a "night watchman state" [17]. The latter was supposed to watch lest some fires would burst out at night. A very regulation prone policy style would not search for the guilty, but for those who did not manage to take and enforce relative 
regulatory decisions. From this point of view, we care more about the administrative response than the causes. However crucial the managerial part may be in each case, it is far more important to look for the primary sources of a problem. Managerial effectiveness was not meant to disregard reason and legality. Justice is such: to find the primary causes and suspects. For Aristotle without causes there is not truth. Thus, to blame secondary causes for a bad incident is like handling a scientific matter by ignoring key primary sources-how unscientific!

Equally unfounded is the claim that what is young is necessarily better. Though it was always believed that timely is far better than untimely ("everything is fine on its hour" [18], it was not meant by that that the present belongs to the young, because they are supposed to embody present time. Besides, the Greeks themselves used to say that it is a defeat for a city (-state) to let the elder ruled by the youngsters [19]. In reality, we believe that present time is best captured by those who have a considerable life span behind them, as they do possess much time. Time must be recognized by time, precisely as similar has an affinity with similar-that is why we often use similes. Thus, while we may suppose that young time is captured by the young, the whole (time) must be captured by what has been accustomed with any time. For the present is not just a moment of today; it is rather a moment in history!

Accordingly, policies which wish to transfer enormous power to the youngsters are wrong, not to mention they are untimely. One may argue that such policies as the rights of children have nothing to do with such sophistries as the above; they rather have to do with practical concerns about children's safety. Even so, the legislator would have formulated relative enactments in different terms, terming for instance his/her act as children protection act. For, an insistence on children rights may suggest that what is at stake is an inherent violence on the part of parents and, hence, children's custody should be shared with the state. In addition, such legislation contradicts with some other existing one which forbids non adults to engage in particular market transactions and/or exercise political rights.

A similar fallacy may be observed when equality, crudely applied, gives rise to laws that are not in accordance with other real social relationships. Such are laws which try to regulate home violence, but do not recognize the role played by human passions and sentiments. Whereas in other cases improper speech is restricted (e.g. case of special minorities), this rule does not apply to families. Nor is it recognized that problematic behavior may not be confined to males. Yet, a search on world literature (fiction and theatre) may convince us that various female roles are in reality existent, both "good" and "bad" $[20]$, or that conflicts among women are not rare because of different interests and points of view, different education levels, or sheer preferences and emotional stances (see. e.g. Sophocles' dramatic play "Helectra"). In practice, all good principles cannot be evoked at the same time, as said above: There are cases in which economic rights are far more important than issues of violence. Thus, a divorced woman who has got rid of a violent husband cannot be benefited from home violence legislation. Instead, she is in need of a good salary. If, however, horizontal measures of income curtailment are taken, the role of women disappears altogether. Such mass policies fail to do justice to special social categories. Let me remind here that the number of single parent households is quite high across the Western world.

Family issues are also regulated through demographic policies. Population itself matters when we view countries as a whole. Rousseau had elevated the demographic factor into a key criterion of good governance [2]. That is why across EU family policies are pursued. The real problem is, of course, that as the rule of conflicting ideas applies here too, should we try to become more competitive by decreasing the labor cost, or favor births? To be sure, all kinds of policies are formally pursued, as it is shown by a typical diagram of an average public administration. Yet, it is well known that some departments get less share than other departments. To dramatically increase demographic policy's budget would depend upon the idea we have about it. At the end of the day the relative decision would depend upon this issue: Is really a population's increase a resource capable of boosting an economy? The answer would be probably positive, as we apply policies of increasing labor force. Yet, this would also be of other departments' concern, for instance, immigration's one, or foreign policy's.

The previous example also highlights the problem of intense departmentalization of public policy which has, of course, been raised on several occasions and tried to be tackled, e.g. through inter-ministerial cooperation and coordination. Let me though add this example: Is there a correlation of the income level with the education standards? If there is, a high education standard should be matched by high income (as measured by per capita). Put this in other words, a country which avails respectable education should be considered to be rich (conf. with the notion of "knowledge society"). It would make a rare exception a country with good education and low per capita income, as both international measurements and ancient wisdom suggest that education goes hand in hand with good income, or education is equivalent to good income. A failure on that implies that there is a tremendous gap between real skills and pay in the labor market. It would also suggest a failure in the value system as well as the politico-administrative one. In other words, either education is not valued much, or it cannot be utilized-maybe because of extreme clientelism-itself a sign of underdevelopment.

Having thus far examined fallacies associated with sex and gender, population and education misconceptions, we could now turn our attention to problems arisen out of wrong ideas about law itself. For example, there is still such a vague idea as that all constitutions are class based, something which may lead to false assumptions and hence decisions. For example, there are constitutions which are established as a result of a major regime change and hence reflect a multi-party consensus. In such cases it may be proved that electoral majority is not translated into ideological majority. Some other times, the governing elite itself may decide to revise the constitution, just because it wishes to add to its political 
capital. Greeks used to say that all matters depend upon and are bound to be regulated by three factors: Law, Habit and Need [21]. Therefore, some decisions are made just by ambition and a need to become distinguished. This natural human tendency has nothing to do with class interests, but rather with a will to enhance a curriculum vitae. Finally, such initiatives may have to do with immediate political tactics and expediencies. This may be much more so, when we live in spectacle societies which live upon events much more than class interests. In any event, the latter may be just one option within a multidimensional political game.

Furthermore, if ideas about law may often be mistaken, similar problems may be found in relation to historical assumptions. We may take notice here that history is not irrelevant to policy making, particularly as recent changes in borders have taken place and immigration pressures abound nowadays. Historical beliefs stand for right claims, a fact which proves that law cannot be entirely separated from history and affinitive sciences, e.g. philosophy and social science-the latter play the part of the interpreter. Thus, we read and understand history according to the idea we have about it and therefore there are some fact based historical schools and others which are more interpretative. In any event, historical arguments which are eligible for political bargaining is widely accepted that they must be well founded, as happens in common cases brought before a court. History resembles individual history (CV). When history becomes an idea, it is less documented, albeit ideas help to organize scattered data-sources. For example, you may wish to write a book on organized interests in a particular area. It is not enough to gather a large number of sources; you will need a theoretical scheme in order to make sensible use of them. A clearly empirical work would probably lead to chaos and, hence, despair you-it is for this reason that the Greeks equated infinity to "evil". Such organizational schemes as "corporatism", "pluralism" and "political system" will probably rescue you. In addition, they will stand for precedents just like they do in courts of justice. Besides, what precedes is superior to what follows from this, for the former usually contains the latter [1].

Thus, in international disputes we try to use such conceptual means in order to settle them. When now we are in lack of written sources, we usually take recourse to other philological means such as the metaphor, or the simile. We may also seek the "ultimate judge", in other words human logic-thought (illogical thought is non -existent). When, for instance, we lack good written sources about a historical event-official History is after all written history-in analogical terms we do not avail a written law, we may well try to think along the afore mentioned lines. To test our recollections, we may seek evidence in tradition, or other means of communication such as visual or oral arts. In some way we shall try to look if there is something resembling custom (formerly a vital source of law). Thus, in the case of Sophocles" "Antigoni" we wish to think that the heroine was right to evoke oral tradition and custom. Similarly, we must not be content with simply dismissing possible and tradition based events such as past sacrifices or exceptional hardships, unless checking them via secondary sources. For example, if there is need to search for the possibility of an oft heard event which is now disputed (say if holocausts in Arkadi, Messologi, or Souli really took place during the Greek liberation war), we will tend to look for such sources as an old painting, or a poem which "thrill" about them (thus, the Greek word "thrillos", i.e. a story of heroic acts which is based on oral tradition, or, literally, a legend). At the same time, as rational human beings we will look for analogous precedents and at the end of the day we shall think about practices relative to mass slavery and war, especially of past times. Just in case all evidence fails, we will not rule out a possibility, for what is not written is not necessarily absent. A fair verdict on such cases might not take the form of a vertical negation, but rather the form of a strong possibility/probability. If we are always after strong written evidence, then we must abandon all our experiments about reconstructing our human species' unwritten history, i.e. Prehistory. We must cease making sense of pre-historical drawings, myths, etc. Equally, we must cease theorizing about the origins of the universe, forgetting perhaps that it is probably some billion years old.

To try to be accurate and fair in our judgment and, consequently, fairly evaluating is of paramount importance in modern administration. It looks so much so as normative evaluation is no longer much descriptive as it is technical-quantitative. The emphasis on technical models of evaluation, applying to both organizations and persons (members of labor force), signifies exactly a disappointment with subjective judgment set down in narrative terms (i.e. a disappointment with authority) and a preference for more "objective" criteria based on "categorical prescriptions". These lead a point of perfection when they can be answered by yes/no, or a figure. This is another manifestation of "arithmetic democracy", or simply democracy, as the electoral style is applied to non-political options as well. Impersonal methods are usually treated as more objective; rhetorical methods based on causality are no longer held reliable. When an electorate is called to decide over a government, we use an impersonal method. Impersonal evaluation is similar to this. However, in order to achieve it, we have to suppress some somewhat personalization factors which designate decision over qualitative matters. Ideally, to reach similar quantifiable results, we would have to erase the possibility of some differences altogether. This is like trying to reach consensus over a particular matter by any means. That is why in a recent work of ours we argued that a consensus system is necessarily a regulatory one [2].For, the regulatory state is one which uses indirect and impersonal techniques (conf. with the notion of "governing without government" [22]) as well as, to this end, especially annoyed by differences. The above mentioned case of making new history really complies with this general paradigm, as it cannot "tolerate" exceptional events (differences). In addition, the more it aspires to reach international consensus, the more it tends to eliminate annoying events. It must be noted here, however, that a "regulatory History" is not true history. Real consensus must be sought via mutual acceptance of events, however unusual 
they may be. To avoid them is as if we pretended there was not war at all. A similar case in the area of education would suggest that no one is distinguished $a b$ initio, for the particular evaluation model does not accept such differences.

Thus, through technical objectification we may be led to apply arithmetic equality to wrong cases. It is often heard that in a democracy various distinctions cannot be accepted, e.g. discriminations based on gender, ethnicity, sex, etc. On the other hand, age is often a discriminatory attribute in some cases. In political battles, for instance, every leader is apt to choose the most attractive attributes. Yet, this prerogative seems to be rejected in other policy areas. To really test the validity of the arithmetic equality principle, we would exactly try it in politics which is the Lydian Stone (i.e. the ultimate test), according to the ancient Greek tradition. On the contrary, we seem to defy it, as we try to incorporate into the selection process the "spectacle society". Though, we understand the pragmatism of the issue, we, at the same time, must recall something which is today unthinkable. Thus, according to Aristotle, "participating in the constitution", i.e. the right to be elected, or placed in a political position was a key criterion of a citizen's attribute as well as an accepted political system (polity) [23]. Though we do not follow a participatory model of democracy today, political representation must, in my view, be based on important selection criteria. What I would suggest in this respect is rationalizing selection process in a mandatory way, by creating a process of pre-selection based on criteria of relevance "for the job". Then the selection committees of the various political parties would have to take on a good percentage of the pool of preselected citizens. Moreover, though further details of this proposal cannot be spelled out here, we should recognize that our current selection system is outmoded and amateurish.

Selection in the labor market and some aspects of labor relations suffer from similar inadequacies. Although here much more progress has been made, some practices look outmoded. If demand and supply must be brought into some symmetry, this being for the benefit of the whole economy, then qualifications matter. Let suppose that a job vacancy can be formally filled by plural candidates. If the selector decides to hire someone who fulfills job requirements at an average level, because all candidates are formally equal, the resulted outcome will most probably bring about the average. Furthermore, if we suppose that this is a widespread practice in a society, we cannot expect but a total average. In other words, human resources are underutilized. We often find it comfortable to leave our capital unaltered, because continuous innovation here is extremely costly. We tend, however, to treat human capital likewise, although this has been made by someone else-someone else has labored to continuously innovating, if with the aid of the state, or his/her family. It naturally follows that we must learn to borrow human capital wisely. Let me add here that good performance at school is usually matched by an honest character, for scientific progress is made by truth loving techniques. A quality of this kind contributes to necessary for every employer confidentiality and commitment.
Yet, another fallacy, coming from some popular, but rather erroneous ideas, is the equation of successful career with cleverness and adaptation. Yet, continuous adaptation cannot produce continuous innovation-if by the latter we mean really new ideas, not ideas which reinvent the wheel. To reinvent the wheel, just adding minor modifications, may be clever, but not really productive. For, when it comes to important issues we find it difficult to produce good solutions. Unfortunately, most companies, or public organizations, tend to face complex problems which, when handled at an average level, bring about a new set of problems. Thus, we may be content with particular solutions given to international disputes, but, when these create further frictions, or grievances, we tend to change our minds. This in itself proves that politics is rarely a positive sum game, as we remarked above. It also proves that politics of compromise is not always the best solution. In my view, a successful conclusion of a dispute is one in which an answer concomitant to a higher idea has been given. I do not regard as successful a conclusion which refutes logic. If, for example, a larger and coherent state entity is better than a smaller and divided one, this principle must be applied, not a deviant one. Similarly, an agreement which fails to satisfy a major power involved is a prelude to future major troubles (conf. with other principles advanced by Aristotle).

To close this indicative list of fallacies, we reserve a final note on redistributional policies such as social insurance/pension ones. First, we must admit that the latter do not form the cornerstone of redistribution, for the desired effect is quite often offset by the power of the effects of other public policies relative to public interest, or local interests. Such is the case of delimiting lands for environmental reasons which may produce quite unequal value results, thanks to selective land depreciation. Similarly, selective public, or private investment may produce several revenue inequalities. Unless such policies are cleverly coordinated, the redistributional result of the welfare state is bound to be equaled to a minimum income guaranteed policy.

Secondly, it seems to us that the principles of social compensation and social equality are not well applied. This is because labor spent must be more accurately calculated. The current method followed to calculate the time and the pay of a pension is quite crude, as it does not acknowledge the basic distinction between knowledge based economy and labor based one. We think that a method of accumulation of skills and qualifications would better suit the issue. As in some issues we decide to apply a qualified majority voting principle, contrasting them to simpler issues to which we apply a simple majority formula, so must we do, mutatis mutandis, in the case of pension rights.

\section{Conclusion}

Truly it is not very nice to judge someone upon failures only. Yet, we may reasonably argue that it has become a vogue lately, perhaps because of a kind of thinking borrowed from the media and/or similar digital languages. For instance, to press a wrong button may often amount to a disaster. It 
certainly counts as a failure. For, often you do not have a chance to return and correct it. This failure to recall and correct suggests decisions depending upon minor moves and mistakes look like traps. Under such circumstances, rational and well prepared decisions cannot easily be reached. In reality, however, much has been reached, despite such kind of doing things. Most public administrations have quite often delivered planned outcomes.

On the other hand, as e-democracy has helped to intensify accountability via increased pressure-due to such factors as discussed above-public administrations have also marked by failures. An additional reason for that is some kind of misinformation about key political concepts. Loosely, or mistakenly understood, they have contributed to some wrong decisions. Quite often these are presented as a matter of choice which is, of course, true in multiparty democracies. Yet, when we note a lack of clear purpose and particular contradictions associated with it, we can attribute the failure to misconceptions. At other times, so called populist policies, characterized as such by a wish to flatter either national, or international audiences, are to blame for particular failures.

Closing this article, we would argue that the list of policy deficiencies cannot be exhausted, but in a quite lengthy treatise Here we had the opportunity to address the problem, offering a few examples. In addition, we tried to show that public policies originate from ideas which take flesh and bones by law makers and policy makers. The role of the latter is very important, because they have to cope with the difficult task of accurately translating vague ideas, but also picking among various and often conflicting ideas (principles). While choosing the means is part of our "curse" as free living creatures (our damn freedom?), without good principles we would resemble those who navigate amid darkness with no lighthouses whatsoever. As a Greek thinker had put it, every city has a few persons who are like lighthouses: they offer much light by little means (Epiktitos [24]).

\section{References}

[1] Aristotle (2002), Rhetoric, transl. by D. Lypourlis, Thessaloniki: Zitros.

[2] Kioukias, D. (2018), Learning and Going Further: Selected Classics and Modern Politics, Lambert Academic Publishing.

[3] Kioukias, D. (2006), European Political Systems and Interest Groups, Athens: Sideris (in Greek), pp. 23-24.

[4] Moulakakis, N., ed. (1997), Ancient Greek Sayings, vol. vi, Athens: Epikairotita (in Greek), p. 54.

[5] Vidali, S. (2019), Crime and Society, Athens: EAP (in Greek).
[6] Hart, J., "Three Approaches to the Measurement of Power in International Relations", International Organization, no. 30.

[7] Allison, G. (1971), Essence of Decision, Boston: Little Brown.

[8] Owen, D. (2015), In Sickness and in Power, transl. by R. Kokoliou, Athens: To Vema (in Greek).

[9] Churchill, W. (2010), The Second World War, ed. D. Kelly, transl. by G. Kastanaras, N. Faliro: Govostis/Kathimerini (in Greek).

[10] Rousseau, J. J. (2005), The Social Contract in Selected Writings, London: The Collector's Library of Essential Thinkers.

[11] Hesse, K. (2017), The Constitution of Political Unity and Practical Harmonization, transl. by I. Koutnatzis, Athens: Papazisis (in Greek), p. 47.

[12] Kioukias, D. (2006), European Political Systems and Interest Groups, Athens: Sideris (in Greek), pp. $72 \mathrm{ff}$.

[13] Plato (n. d. a.), Polity, transl. into modern Greek by G. Gryparis.

[14] Triantafyllopoulos, I. (1968), Greek Legal Systems, Athens: Sakkoulas (in Greek).

[15] See, for example, Hobsbawm, E. (1994), Age of Extremes: The Short Twentieth Century 1914-1991, London: Michael Joseph.

[16] Kioukias, D. (2011) "Readings in Greek Political Fiction: Methods and Relevance to the Modern Political Scientific Inquiry", ECPR General Conference, Reykjavik (http://new.ecpr.eu/Events/PaperDetails.aspx?PaperID=8943\& EventID $=1$.

[17] Locke, J. in Ball, T. \& Dagger, R., eds (1991), Ideals and Ideologies: A Reader, New York: Harper Collins, pp. 77-81.

[18] Moulakakis, N., ed. (1997), Ancient Greek Sayings, vol. ix, Athens: Epikairotita (in Greek), p. 85.

[19] Moulakakis, N., ed. (1997), Ancient Greek Sayings, vol. vi, Athens: Epikairotita (in Greek).

[20] Kioukias, D. 2007, An Introduction to the Social States: Comparative Approaches and Practical Philosophy, Athens: I. Dideris, pp. 37-51.

[21] Moulakakis, N., ed. (1997), Ancient Greek Sayings, vol. vi, Athens: Epikairotita (in Greek), p. 41.

[22] Rhodes, R. A. W (1996), “The New Governance: Governing without Government”, Political Studies, 44 (4).

[23] Aristotle (2019), Politika (Political Affairs), transl. by D. Papadis, Thessaloniki: Zitros/To Vema.

[24] Moulakakis, N., ed. (1997), Ancient Greek Sayings, vol. vi, Athens: Epikairotita (in Greek), p. 65. 